\title{
Cement slurry resistance to chemical aggressiveness of carbon capture and storage (CCS) method
}

\author{
Malgorzata Formela ${ }^{1,}$, Slawomir Wysocki ${ }^{1}$, and Rafal Wisniowski ${ }^{1}$ \\ ${ }^{1}$ AGH University of Science and Technology, Faculty of Drilling, Oil and Gas, 30 A. Mickiewicz Av., 30-059 Krakow, Poland
}

\begin{abstract}
Nowadays, scientists from all over the world are focused on environmental issues connected with the greenhouse gases. The carbon dioxide is one of those gases. Therefore, researches are carried out to limit the emission or utilization the already ones. The aim of laboratory research was to find additives and admixtures resistant to $\mathrm{CO}_{2}$ presence and at the same time, able to modify rheological parameters of fresh cement slurry, as it is desirable during cementing of the wellbore. Moreover, research included the effect of newly synthesized polymers on the cement parameters. Laboratory research included filtration of the cement slurry, rheological parameters Yield point, mechanical properties of hardened cement slurry obtained from hydraulic press and photographs of changes in mineralogical structure of cement from the electron microscope. The research was divided into two parts. The first one was based on the cement mixtures with commonly used superplastifier (SPL). In the second one, the SPL was replaced with newly synthesized polymer.
\end{abstract}

\section{Introduction}

The greenhouse gases are causing the climate change of our planet. Among them, there is carbon dioxide which is produced in vast quantity by all of the factories in the world. Nowadays, there are growing numbers of published articles about possible methods which describe, how to dispose of this gas from the atmosphere. One of those methods is Carbon Capture and Storage (CCS). The main idea of this method is to inject carbon dioxide spotted from the atmosphere into geological formation. Geological sequestration of aggressive $\mathrm{CO}_{2}$ is causing many problems in petroleum industry, mainly with necessity of using anticorrosive materials, especially in cement slurries. To overcome the aggressiveness of $\mathrm{CO}_{2}$ in compound of cement slurry, special additives and admixtures are used. This way, properties of the cement slurry can be modified to withstand chemical influence of carbon dioxide in high pressure and high temperature (HPHT) environment.

One of the methods of utilization is Carbon Capture and Storage (CCS). Carbon dioxide can be sequestrated with the following methods [1]:

$\checkmark$ physical (e.g. geological deposition);

$\checkmark$ chemical (e.g. mineral carbonation);

$\checkmark$ biological (e.g. growing forests).

Geological deposition of $\mathrm{CO}_{2}$ can be realized through (Fig. 1):

a) deposition in deep salt aquifers (they have the highest potential and still remain useless for other purposes); b) deposition in depleted beds of hydrocarbons (potentially with Enhanced Oil Recovery (EOR), or enhanced natural gas recovery);

c) deposition in deep coal beds (not extracted) with Enhanced Coal Bed Methane Recovery (ECBMR) $[2,3]$.

Geological deposition must be conducted with special care to ensure environmental safety. Deposition of $\mathrm{CO}_{2}$ must be taken into account at any stage of operation, including planning and realization.

$\mathrm{CO}_{2}$ leakages through hardened cement slurry to the rock mass are generally caused by carbonate corrosion due to the presence of an aggressive $\mathrm{CO}_{2}$. The mechanism is based on ions migration. Calcium ions, form $\mathrm{Ca}(\mathrm{OH})_{2}$, are leached out of cement, constituting one of the products of hydration of basic components of Portland cement (alite and belite), then also hydrated silicate (C-S-H) and hydrated calcium aluminate [4].

Moreover, the composition of cement slurry should be appropriately selected and the role of $\mathrm{CO}_{2}$ in the development of technological properties of fresh and hardened cement slurry must be determined. It is known that the negative impact of $\mathrm{CO}_{2}$ on the properties of fresh and hardened cement slurry may disturb the exploitation of the well and create considerable hazard for the geological storage of carbon dioxide [5-7].

\footnotetext{
* Corresponding author: mformela@agh.edu.pl
} 


\section{Overview of $\mathrm{CO}_{2}$ Sequestration Technology}

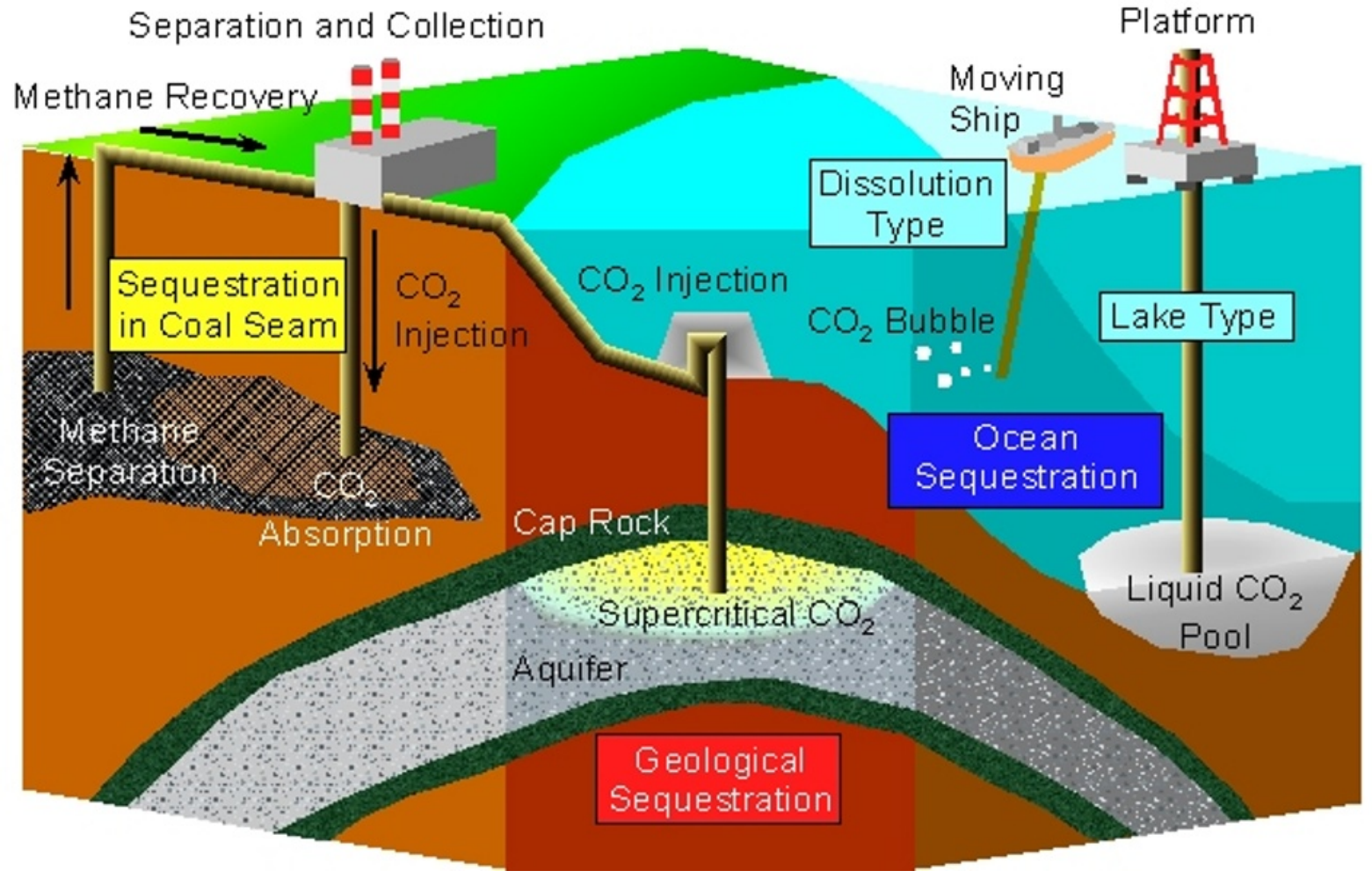

Fig. 1. Potential approach to geological deposition of $\mathrm{CO}_{2}[1]$.

\section{Carbonate corrosion}

Geological structure of rock, where deposition will take place, physical and chemical processes taking place there, and also infrastructure, should be well known to assess possible pathways for leakage of carbon dioxide. $\mathrm{CO}_{2}$ leakage may occur even through hardened cement slurry. This kind of leakage refers to all types of geological storing. Taking this into account, the composition of cement slurry must be resistant to the aggressive environment as such the presence carbon dioxide in the well $[8,9]$.

One of the biggest issues of CCS is social acceptance. Due to the danger of potential leakages connected with geological deposition of $\mathrm{CO}_{2}$, people are not willing to approve this kind of measurements to reduce the greenhouse effect.

Carbonate corrosion or acid-carbonate corrosion is causing cement slurry damage in the geological deposition of $\mathrm{CO}_{2}$. Carbonization begins with cement hydration products, then calcium ions are leached out of cement slurry, first from $\mathrm{Ca}(\mathrm{OH})_{2}$, and gradually as it is washed out, also from hydrated silica, hydrated calcium aluminate and hydrated calcium sulfate-aluminate [3, 4].

The hardiness of cement slurries is also affected by:

$\checkmark$ mineralization of reservoir waters;

$\checkmark$ presence of brines;

$\checkmark$ high temperature.

All products of cement hydration can undergo the carbonation process.
At the first stage of the carbonation, gaseous $\mathrm{CO}_{2}$ is dissolved in water and $\mathrm{CO}_{2}(\mathrm{aq})$ is formed. Then $\mathrm{H}_{2} \mathrm{CO}_{3}$ is formed to dissociate to $\mathrm{H}^{+}, \mathrm{HCO}_{3}{ }^{-}, \mathrm{CO}_{3}{ }^{2-}$. When $\mathrm{CO}_{2}{ }^{-}$ saturated water diffuses to the cement slurry matrix, $\mathrm{Ca}(\mathrm{OH})_{2}$ is dissolved in a carbonic acid solution. Dissolving of portlandite is connected with the migration of $\mathrm{Ca}^{2+}$ ions to the solution, as a consequence of which of $\mathrm{CaCO}_{3}$ is formed [4].

At the initial stage of carbonation cement slurry is sealed under the influence of the hardly soluble $\mathrm{CaCO}_{3}$. The solution in the pores of the slurry (pore fluid) is strongly alkaline, with $\mathrm{pH}$ equal to about 13 . When $\mathrm{pH}$ of the pore fluid lowers as a result of carbonization to about 10.5 , the $\mathrm{CO}_{3}{ }^{2-}$ ions dominate and $\mathrm{CaCO}_{3}$ is stable and durable. At that time the slurry has lower permeability, which results from the fact that part of the pores are blocked with the formed $\mathrm{CaCO}_{3}$. The strength of the hardened cement slurry increases. When portlandite and alkaline phases are depleted in the cement slurry matrix, $\mathrm{pH}$ of the solution lowers and $\mathrm{HCO}_{3}{ }^{-}$start dominate in the solution. Then $\mathrm{CaCO}_{3}$ dissolves as a result of which $\mathrm{Ca}^{2+}$ ions are washed out from the cement matrix, and $\mathrm{CaCO}_{3}$ assumes the form of calcium hydrogen carbonate. Hardened slurry, devoid of $\mathrm{CaCO}_{3}$, cannot buffer $\mathrm{pH}$, as a consequence of which the hydrated calcium silicate C-S-H loses $\mathrm{Ca}^{2+}$ and take the form of amorphous silica gel.

The formation of amorphous silica gel increases the porosity, lack of coherence (continuity) of 
microstructure of cement slurry, and so lower strength in longer time intervals.

The basic carbonization product is calcium carbonate, which is present in the cement slurry in various phases. Veterite is probably formed first, then it takes the form of calcite with aragonite as a transition state [4].

The mechanical hardiness of cement slurry, which are going to be used in wells for geological storage of $\mathrm{CO}_{2}$, should be thoroughly analyzed, such as its rheological parameters, to guarantee the best possible solution to conduct geological sequestration of carbon dioxide in rock reservoirs. Special attention should be paid to the wells which were not previously dedicated to CCS $[2,3,9]$.

Hardened cement slurry used in wellbores for carbon dioxide storing should have lower fluids and gases permeability [3, 9]. One of the most important factors having effect on the permeability coefficient is the water to cement ratio $(\mathrm{w} / \mathrm{c})$, which influences the capillary porosity. Capillary pores generate flow of aggressive solutions inside the hardened slurry, which may lead to reactions accelerating chemical corrosion. Each change of cement slurry $\mathrm{pH}$ may cause faster or slower decomposition of hydrates. This means that acidic solutions (mainly acids) of low $\mathrm{pH}$ (ca. 5) will make the hardened slurry dissolve. Among the most reactive compounds which quickly react with the slurry hydration products are sulfates and chlorides [4]. Water film gathering on the mineral filler grains increases the porosity on the slurry/filler interface, where many calcium hydroxide particles are present. This leads to the local increase of w/c ratio. This process can be stopped by applying a mineral additive to the slurry, i.e. silica powder containing about $98 \% \mathrm{SiO}_{2}$. Silica powder reacts with calcium hydroxide forming $\mathrm{C}-\mathrm{S}-\mathrm{H}$ phase, which increases the durability of hardened slurry in corrosive environment [4].

The effect of adding silica powder on hydration processes is illustrated in Fig. 2. a)

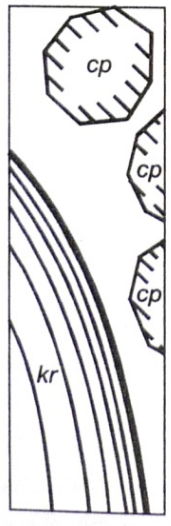

b)

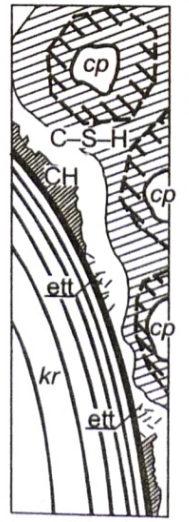

c)

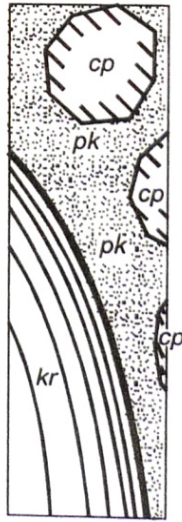

d)

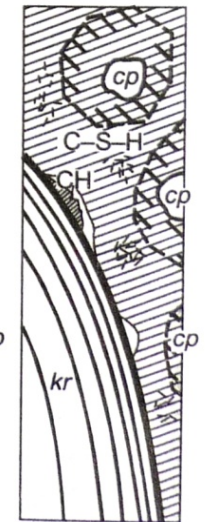

Fig. 2. Influence of silica powder on the build of the slurry. Aggregate interface: $\mathrm{cp}$ - cement grains; $\mathrm{pk}$ - silica powder [4].
The destruction of hardened cement slurry may derive from single or synchronic processes favoring corrosion.

Carbonization process has an effect on the pore structure in the cement slurry. Total porosity is lowered and the distribution of pores is shifted to higher values.

Corrosion develops faster in cements containing over $30 \%$ of fly ashes and $50 \%$ more slag. The influence of the cement type on the depth of carbonization of the slurry is presented in Fig. 3 [4].

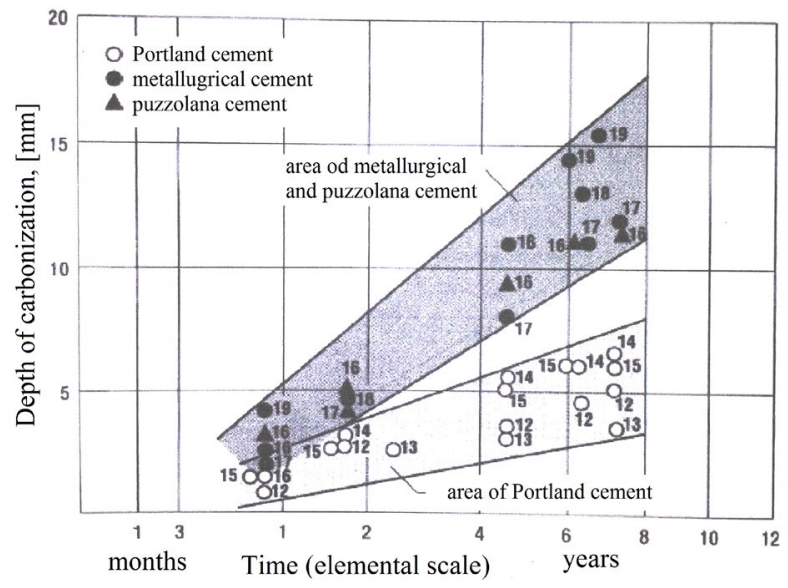

Fig. 3. Influence of cement type on the depth of slurry carbonization [4].

The analysis of figure 3 reveals that carbonate corrosion is slower in Portland cements, where no additives were applied. Hydration of mineral additives is slower than in klinker phases. The changes of porosity and permeability of the matrix are visible only after a longer time of slurry maturation [4].

\section{Laboratory research}

First stage of laboratory research consisted of basic cement slurries composition based on drilling cement $G$ which is commonly known as widespread hydraulic binder for cementing oil and gas wells (standard of the American Petroleum Institute - API). To improve rheological parameters of fresh cement slurry, superplasticizer (SPL) Glenium SKY 591 by BASF Polska Sp.zo.o. (The Chemical Company - Concrete Admixtures Department) use in the slurry equaled to 1.4 and $2.0 \mathrm{wt} . \%$ in reference to the mass of dry cement.

Laboratory analyses of technological parameters of sealing slurries were based on the following standards:

1. PN - EN 197 - 1: 2002, Cement. Part 1. Composition, requirements and congruence criteria of common use cements.

2. PN - EN ISO 10426 - 1. Oil and gas industry. Cements and materials used for cementing wellbores. Part 1. Specification.2006

3. PN - EN ISO 10426 - 2. Oil and gas industry. Cements and materials used for cementing wellbores. Part 2: Analysis of drilling cements. 2006. 
Main laboratory tests were conducted with: the filtration press - the pressure has got $0.7 \mathrm{MPa}$ value and the viscosimeter - value of the rotation speed of the rotor and bob during 300 and 600 [rpm] was measured, then presented as a Yield point. Those parameters are one of the decisive during well cementing process. It is due to the fact, that they value is crucial for ability cement to flow by the steel casing and cross section area of the well. The mechanical properties of the hardened cement slurry, after its seasoning in water or $\mathrm{CO}_{2}$, were tested on the hydraulic press and were chosen for the electron microscope photographies.

In table 1 there are presented compositions of cement slurries used in first stage of the laboratory research.

Table 1. Composition of the cement slurries in first stage of laboratory research.

\begin{tabular}{|c|c|}
\hline No. & Composition of the cement slurry \\
\hline 1 & Cement G (API) \\
\hline 2 & Cement G (API) $1.4 \%$ SPL \\
\hline 3 & Cement G (API) $2.0 \%$ SPL \\
\hline
\end{tabular}

Below there are presented chosen properties of fresh compositions of cement slurries (Figures 4 and 5).

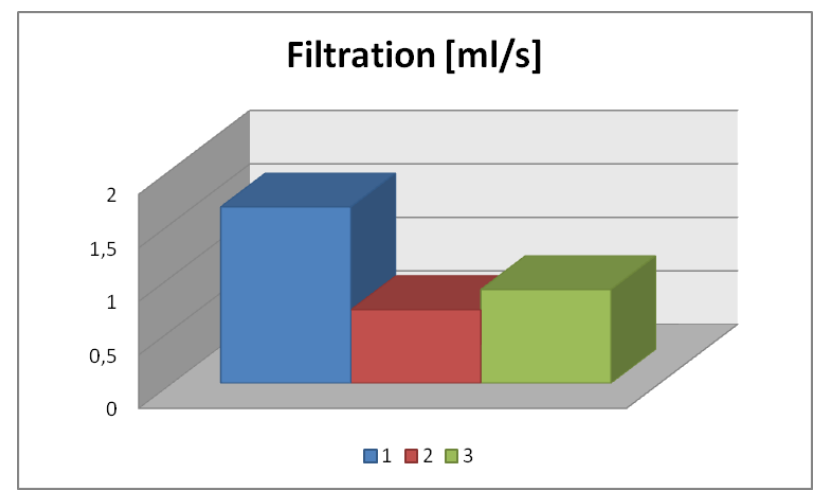

Fig. 4. Filtration of cement slurries.

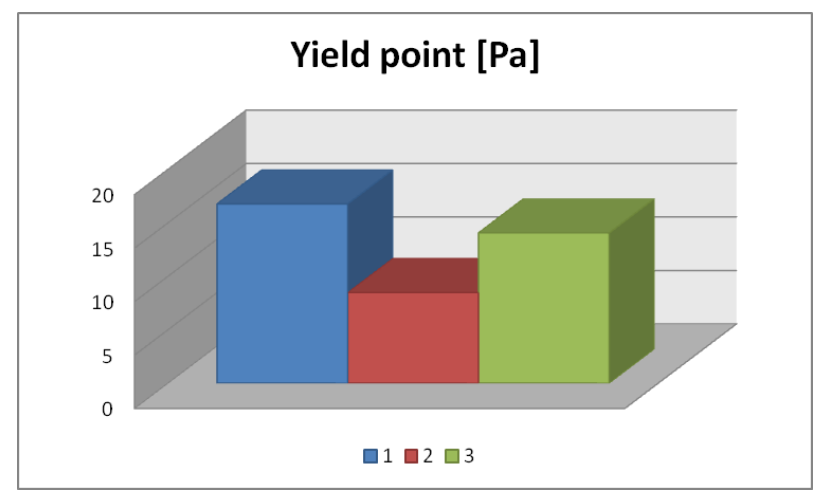

Fig. 5. Yield point of cement slurries.
As is shown, the filtration of cement slurries was not in API standards, thus basics compositions are not suitable for cementing wells intended for geological deposition of $\mathrm{CO}_{2}$ even the yield point of the cement slurry is sufficient for basic cementing jobs.

Samples of basic compositions of hardened cement slurry after corresponding maturing in water or in gaseous $\mathrm{CO}_{2}$, were designed for measure mechanical properties. The results for bending stresses are presented in Figures 6 and 7.

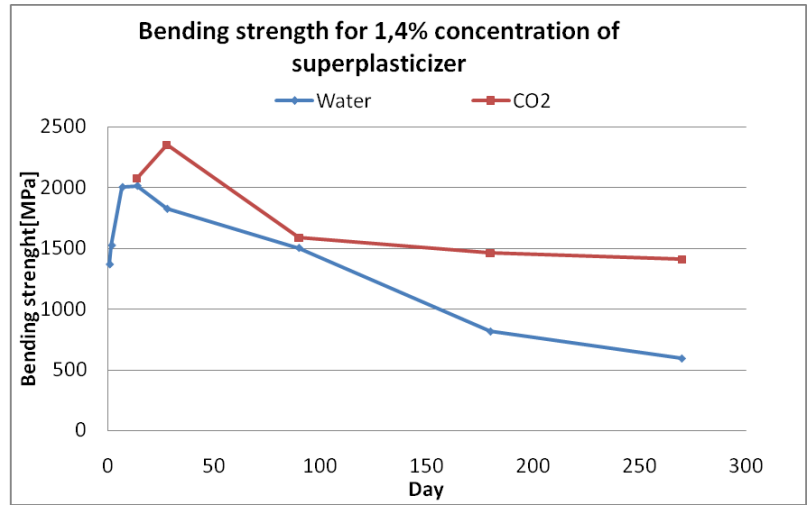

Fig. 6. Bending strength for $1.4 \%$ concentration of SPL for water or $\mathrm{CO}_{2}$ presence after suitable period of time.

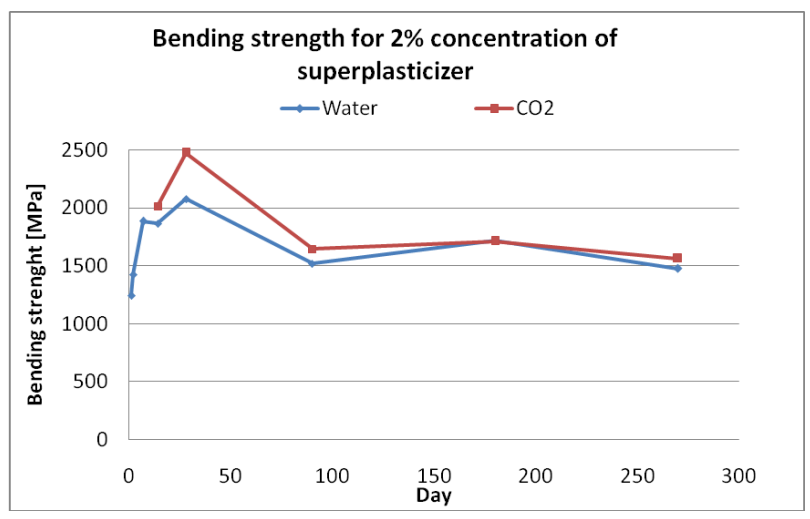

Fig. 7. Bending strength for $2.0 \%$ concentration of SPL for water or $\mathrm{CO}_{2}$ presence after suitable period of time.

Sample of $2.0 \%$ concentration of superplasticizer was also selected for electron microscope photography (SEM) to observe changes in mineralogical structure after seasoning specimens of cement slurries in water (Fig. 8) or gaseous $\mathrm{CO}_{2}$ (Fig. 9). 


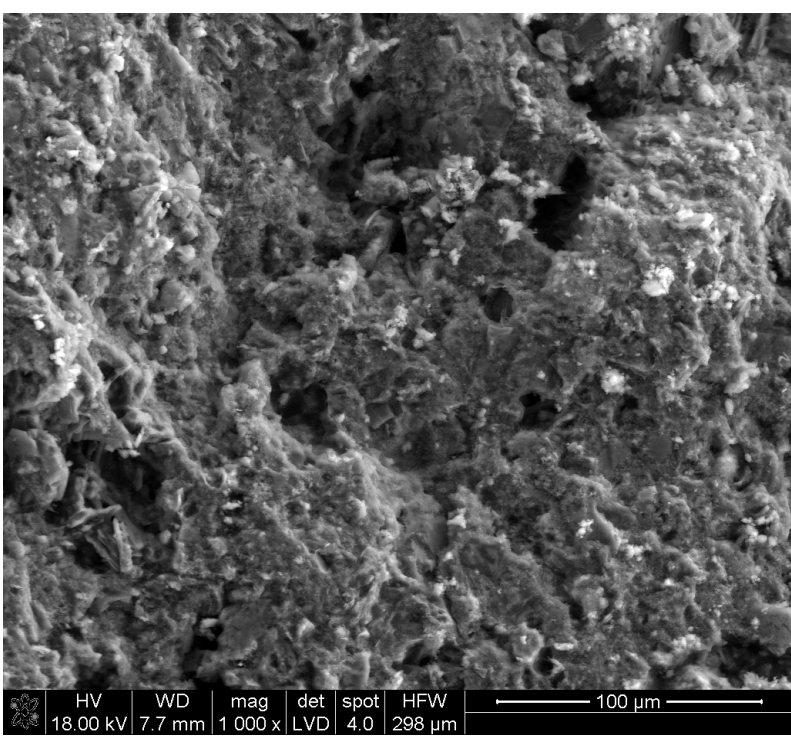

Fig. 8. SEM photograph of sample seasoning in water for 270 days.

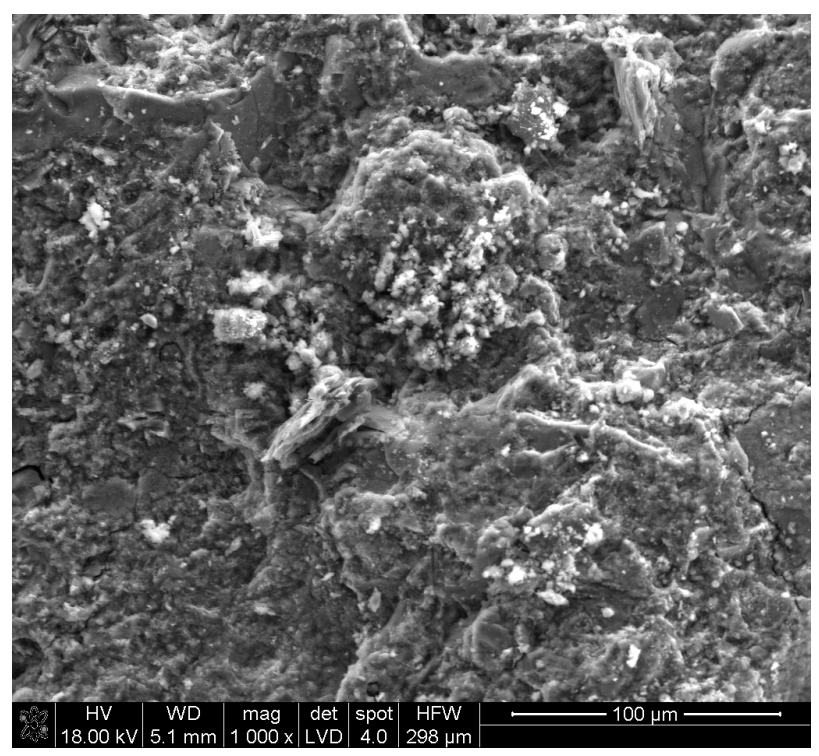

Fig. 9. SEM photograph of sample seasoning in gaseous $\mathrm{CO}_{2}$ for 270 days.

Sample which was seasoning in water has got high porosity which is observed by black areas on the Figure 8 . It can be caused by aeration during cement mixing.

Regarding sample which was seasoning in gaseous $\mathrm{CO}_{2}$, it can be seen carbonization process. It is observed as small puff and pilled surface of the sample. In pores it can be find fine crystalline calcium carbonate aggregates that led to this process.

The aim of the second stage of the laboratory research was to substitute well known superplasticizer by new polymeric agent synthesized at Drilling, Oil and Gas Faculty AGH - UST Krakow. New compositions of cement slurries are presented in Table 2.
Table 2. Composition of the cement slurries in first stage of laboratory research.

\begin{tabular}{|c|c|}
\hline No. & Composition of the cement slurry \\
\hline 1 & Cement G (API) \\
\hline 2 & Cement G (API) $0.5 \%$ SPL \\
\hline 3 & $\begin{array}{c}\text { Cement G (API) } 0.5 \% \text { SPL } \\
0.5 \% \text { filtration regulator }\end{array}$ \\
\hline 4 & $\begin{array}{c}\text { Cement G (API) } 0.1 \% \text { polymer } \\
0.5 \% \text { filtration regulator } 0.5 \% \text { defoamer }\end{array}$ \\
\hline 5 & $\begin{array}{r}\text { Cement G (API) } 0.5 \% \text { polymer } \\
0.5 \% \text { filtration regulator } 0.5 \% \text { defoamer }\end{array}$ \\
\hline
\end{tabular}

At secondary stage of the laboratory research there was conducted filtration of cement slurries. As a result of using filtration regulator in $0.5 \%$ addition in composition of cement slurries, the filtration fulfill the requirements of API standards. The results can be found in Figure 10.

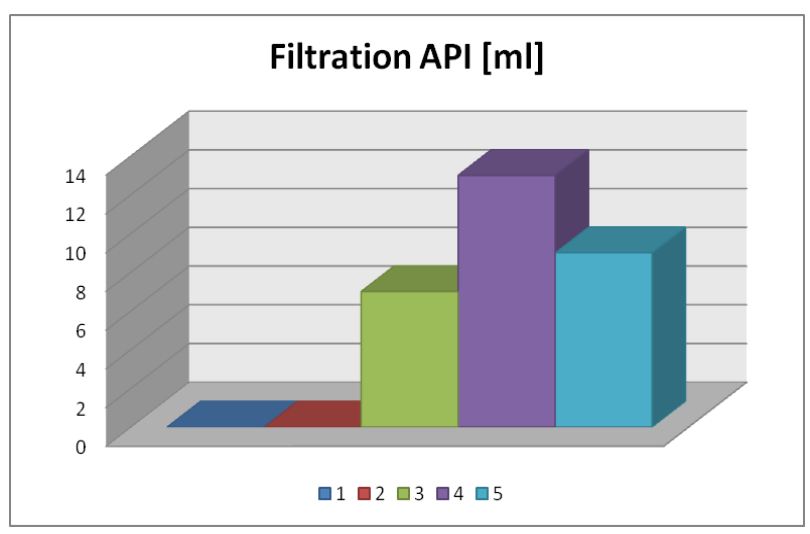

Fig. 10. Filtration of cement slurries.

In Figure 11 there are shown results from measurement of yield point.

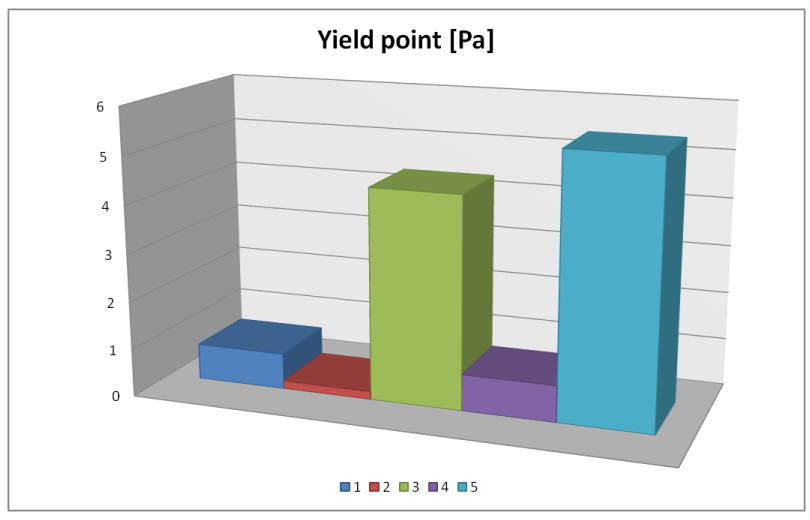

Fig. 11. Yield point of cement slurries.

The last measurements which was conducted in second stage of the laboratory research were gel strength 
after 10 seconds and 10 minutes (Fig. 12) for all 5 compositions of cement slurries.

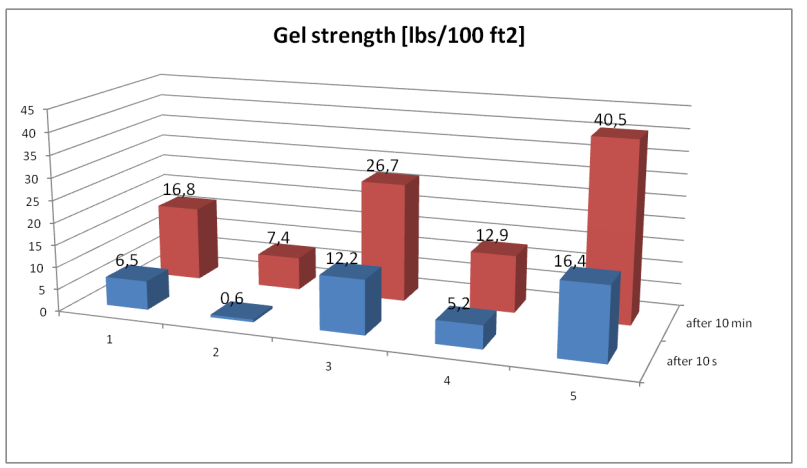

Fig. 12. Gel strengths of cement slurries.

As it is shown on the Fig. 12, gel strength changes its value regarding quantity of the additives. It can be seen, that when commonly used superplasticizer and filtration regulator are in the mixture (sample 3), the value of gel strength is higher than in the base sample (sample 1). But when there is used a newly synthesized polymer (in the same amount as SPL), the gel strength has got higher value. This observation can lead to better cement flowing during cementing process.

\section{Conclusions}

Negative effect of aggressive environment on cement slurry, i.e. carbon dioxide, requires extensive studies of its impact on technological parameters of fresh and hardened sealing slurry. In wells where exists the risk of carbon dioxide presence, special attention should be paid to inorganic mineral additives, highly resistant to the corrosiveness of $\mathrm{CO}_{2}$. The increased concentration of the superplastifier in the cement slurry, from 1st stage of the project, considerably changed mechanical properties of hardened cement slurry. The microscopic analysis of the selected sample reveals that the presence of carbon dioxide does not lower the bending strength of the slurry, what is more, it considerably increases these parameters. To reduce filtration of the cement slurry there was used polymeric component. As a result, filtration of the cement slurry was limited and complies with API (American Institute of Petroleum) standard. Newly synthesized polymeric agent, used instead of the commonly known superplasticizer, positively affected the fresh parameters of cement slurry. Therefore, samples will be studied for mechanical properties and mineralogical changes.

Work realized at the Department of Drilling and Geoengineering, Faculty of Drilling, Oil and Gas AGH-UST within the Statutory Research Program No. 11.11.190.555.

\section{References}

1. https://www.picswe.com/pics/co2-sequestration38.html (21.11.2018r.)
2. A. Uliasz-Bocheńczyk (Ed.), The underground storage of $\mathrm{CO}_{2}$ with ash-water suspention (Mineral and Energy Econoy Research Insitute, Kraków, 2007, in Polish)

3. A. Uliasz-Bocheńczyk, Cement slurries in the drilling technolgies of $\mathrm{CO}_{2}$ geological storage (Mineral and Energy Econoy Research Insitute, Kraków, 2012, in Polish)

4. W. Kurdowski, Cement and concrete chemistry (Wydawnictwo Naukowe PWN, Kraków, (2010)

5. S. Stryczek, W. Brylicki, J. Małolepszy, A. Gonet, R. Wiśniowski, Ł. Kotwica, Ninth CANMET/ACI international conference on the Use of fly ash, slag, silica fume and other supplementary cementing materials in concrete technology, Warsaw, Poland, May 20-25 (2007)

6. S. Stryczek, J. Małolepszy, A. Gonet, R. Wiśniowski, Ł. Kotwica, The influence of ineral additives on technological properties of sealing grouts used in drilling and geoengineering (Wydawnictwo S.C.M.R, Wioska z Chorzowa, Kraków, 2011 in Polish)

7. S. Stryczek, J. Małolepszy, A. Gonet, R. Wiśniowski, Ł. Kotwica, A. Złotkowski, J. Ziaja, Ashes from fluidal bed combustion of brown coal an additives for sealing slurries (Wydawnictwa AGH, Kraków, 2013, in Polish)

8. R. Tarkowski, Geological sequestration of $\mathrm{CO}_{2}$ (Mineral and Energy Econoy Research Insitute Kraków, 2005, in Polish)

9. A. Uliasz-Bocheńczyk and E. Mokrzycki, Wiertnictwo Nafta Gaz 22, 373-378 (2005) 